\title{
Comprehensive evaluation of water-use efficiency in China's Huai river basin using a cloud-compound fuzzy matter element-entropy combined model
}

\author{
Xinjian Guan, Haidong Qin, Yu Meng* and Zening Wu \\ School of Water Conservancy and Environment, Zhengzhou University, No. 100, Science Avenue, High-Tech Zone, \\ Zhengzhou 450 001, People's Republic of China. \\ ${ }^{*}$ Corresponding author.e-mail: mengyu8@zzu.edu.cn
}

MS received 2 August 2018; revised 27 January 2019; accepted 16 April 2019; published online 24 June 2019

We are facing the water shortage crisis. To realise sustainable development, we should improve water-use efficiency (WUE). In this study, a cloud-compound fuzzy matter element-entropy combined model was constructed to evaluate WUE. The Huai river basin (HRB) was selected as the study area. The cloud model was used to select some indices and build the comprehensive evaluation index system (CEIS), which included the overall, agricultural, industrial, domestic and environmental categories. The compound fuzzy matter element model was used to calculate the comprehensive indicators of WUE of the HRB and its regions. The weight of each index in the CEIS was determined using the entropy model. The results showed that WUE of the HRB had an upward trend on the whole because of the enhanced emphasis on water resources by the international and national governments. However, the regional difference was obvious. The WUE of Henan province was higher than that of Jiangsu province. The imbalance of regional WUE is an international problem. By analysing the difference among regions, research can provide a reference for the decision making of the water resources management department.

Keywords. Water-use efficiency; cloud model; compound fuzzy matter element model; entropy model; Huai river basin.

\section{Introduction}

Due to population growth, economic development, changing consumption patterns and other factors, the global demand for water has been increasing at a rate of about $1 \%$ per year, which will continue to accelerate over the next 20 years. Currently, nearly half of the global population is living in water-decient areas. According to this development, the population will increase to $4.8-5.7$ billion by 2050 (UN 2018). Six out of the 17 sustainable development goals relate to water, and Goal 6 is 'Ensure availability and sustainable management of water and sanitation for all'. To solve the problem of water shortage and drastically reduce the number of people who suffer water shortage, it requires the implementation of integrated water resources management at all levels, by significantly increasing water-use efficiency (WUE) across all sectors and ensuring the sustainable supply of fresh water (UN 2015b). Therefore, the sustainable use of water resources is very important to the development of social economy and the protection of ecological environment. The research on WUE supports the efficient and sustainable utilisation and management of water resources.

The study of WUE involves agriculture, industry, living, ecology and other aspects related to 
social and economic development, human life, urban construction, ecological and environmental health (Karimi et al. 2012). As for WUE, people not only need to deeply study the technical appraisal of a single industry, but also attach importance to a comprehensive evaluation of multiple industries. The index comprehensive evaluation method is composed of the comprehensive evaluation index system (CEIS) which is involved in a certain aspect of the comprehensive evaluation model. The comprehensive model is used to convert all indices in the CEIS into a representative comprehensive indicator, so as to comprehensively evaluate the aspect analysed. The WUE of multiple industries can be well integrated into an overall situation, which is convenient for analysis.

For the study of WUE, more evaluation indices have been proposed in each industry. Among them, more attention has been paid to agricultural indices, such as yield per unit of water used (Playan and Mateos 2006), the proportion of stored soil water transpired by crops (Moore et al. 2011) and irrigation water consumption (Sadras et al. 2012). With the development of industrialisation, industrial water consumption is constantly increasing. The evaluation of industrial WUE focuses on the utilisation rate of recycled water (Fujii et al. 2012) and the water consumption of industrial output (Guo and $\mathrm{Fu}$ 2010). Although the proportion of domestic water use is small, it is necessary to evaluate domestic WUE as the population increases, which mainly emphasises the water consumption per capita (Keshavarzi et al. 2006). As the economic and social development has been placing much pressure on ecological environment, more and more attention has been paid to the research on environmental WUE, but the environmental indices of WUE are still lacking (Azad and Ancev 2014).

There is no universal CEIS of WUE at present. It is difficult to systematically analyse each index, because there are many qualitative and quantitative indices related to WUE in each industry. The indices that represent each industry need to be screened from the basic index set (BIS). When filtering indices based on principles of science, quantification, manoeuvrability and representation, certain indices can be selected from the BIS of WUE in each industry, which are combined with the situation of the study area and expert opinions (Lei 2017). The used mathematical methods include the analytic hierarchy process (Yang et al. 2009), the trapezoidal fuzzy number method (Guan et al. 2016) and the cloud model. The cloud model was proposed by academician Deyi Li, which could realise the conversion between the qualitative concepts and quantitative expressions ( $\mathrm{Li}$ et al. 2009). Based on this theory, the cloud model has been successfully applied in data mining, system comprehensive evaluation, intelligent control and image processing (Dong et al. 2016; Wang et al. 2016; Zhang et al. 2018a). Among them, the cloud model can be used for scheme screening and sorting, which shows good application results (Wang et al. 2017; Xu et al. 2018). Index selection by cloud model is also based on the theory. The language qualitative evaluation of indices is converted into the mathematical quantitative score, which is convenient for sorting multiple indices. At present, the index screening based on the cloud model has also been applied. Although the research results mainly pertain to China, the application of the cloud model is worthy of being popularised internationally.

After constructing the CEIS, an appropriate comprehensive evaluation model is chosen to comprehensively evaluate and analyse regional WUE. The determination of index weight is the key link of comprehensive evaluation and plays a decisive role in the evaluation results. Weight evaluation methods are roughly divided into two categories: the subjective evaluation method and objective evaluation method. The subjective evaluation method is to evaluate a thing based on the sample statistics and experience, which is represented by the Delphi method ( $\mathrm{Lu}$ et al. 2016) and analytic hierarchy process (Qin et al. 2014). The subjective evaluation method is greatly influenced by subjective factors and is not easy to test under the related constraints.

The objective evaluation method is to evaluate a thing based on the measured and statistical data of each index. It can avoid the interference of man-made subjective factors and reflect most of the original information of each index. The objective evaluation method is represented by the projection pursuit model ( $\mathrm{Yu}$ and $\mathrm{Lu}$ 2018) and the entropy model (Maruyama et al. 2005). Projection pursuit is to project high-dimensional data onto a low-dimensional subspace to find the best projection direction that can reflect the original high-dimensional data (Christiansen 2009). The entropy model is considered to be one of the most effective models, which uses the amount of information by the entropy value of each index to determine the index weight (Amiri et al. 2014; 
$\mathrm{Wu}$ et al. 2015). The projection pursuit model needs to be optimised during the calculation. The optimisation procedure and results are uncertain, and the optimisation efficiency is also related to the combined optimisation algorithm. Compared with the projection pursuit method, the entropy method has the advantages of simple operation and fast calculation. Currently, most comprehensive evaluation models do not have a clear classification of the comprehensive indicators. It is often classified by subjective judgment or mutual comparison among evaluation objects, which lacks the scientificity of classification evaluation. But the compound fuzzy matter element model can solve the problem. It has been successfully combined with the entropy weight model, projection pursuit model and other evaluation models, and is widely used in the comprehensive evaluation of river health, water environment quality and engineering safety risk (Deng et al. 2015; Pan et al. 2015; Chen et al. 2017; Zhang et al. 2018b). The above successful precedents can well explain the universality of compound fuzzy matter element model. The combination of compound fuzzy matter element model and entropy weight model also applies to the comprehensive evaluation of WUE.

In this study, the WUE covered agriculture, industry, living, ecology and environment. Firstly, the key indices of WUE in each industry are collected, which are scientific, universal and representative, so as to build the BIS of WUE. Secondly, a cloud-compound fuzzy matter element-entropy combined model is constructed, which includes the construction of CEIS, determination of comprehensive evaluation standard and calculation of comprehensive indicators. Finally, taking the Huai river basin (HRB) as an example to verify the feasibility of the theories and methods, the paper aims to provide a systematic quantitative evaluation method for the comprehensive evaluation of WUE, which covers the construction of the evaluation index system, determination of the comprehensive evaluation standard and calculation of comprehensive indicators. The research method of the paper can provide a comprehensive and systematic evaluation process and method support of each link for the comprehensive evaluation of WUE. Besides, the research content provides technical reference for water resources management and strong support for the sustainable utilisation of water resources.

\section{Methods}

\subsection{The BIS of WUE}

WUE involves living, production, the ecological environment inside and outside the river channel and other aspects, so the BIS should cover four major aspects: industry, agriculture, living and ecology and environment. Almost all commonly used and quantifiable indices of WUE were collected from each industry (Keshavarzi et al. 2006; Playan and Mateos 2006; Yang et al. 2009; Fujii et al. 2012). The BIS was constructed by these indices, as shown in table 1 . The BIS provided a relatively comprehensive and optional range for the evaluation of WUE. In practice, combining the actual situation and data support, several indices were selected from the BIS by a scientific method, which constructed the CEIS. There are 25 indices in the BIS. By analysing the property of each index, indices can be divided into two categories, as shown in the third column of table 1 . The symbol $+/-$ means a positive/negative correlation between the index value and the WUE.

\subsection{Cloud-compound fuzzy matter element-entropy combined model}

In the study, a cloud-compound fuzzy matter element-entropy combined model was constructed to comprehensively evaluate WUE. Among them, the cloud model was used to select some indices that met the needs from the BIS, which built the CEIS. The compound fuzzy matter element model was used to transform the indices and index-grade boundaries of the CEIS into comprehensive indictors and comprehensive boundaries. The entropy model was adopted to calculate the weight value of each index in the compound fuzzy matter element model.

\subsubsection{Cloud model}

Let $U$ be a quantitative evaluation set $U=\{x\}$, which is called the universe of discourse, which is composed of the quantitative scores of the horizontal coordinate and the membership of the vertical coordinate. $T$ is the qualitative evaluation related to $U$. By mapping $T$ into $U$, position $u(x, y)$ can be obtained which is defined as a cloud drop. The membership function of $x$ to $T$ is $y(x) \in[0,1]$. The higher the membership degree is, the closer $x$ is 
Table 1. The BIS of WUE.

\begin{tabular}{|c|c|c|}
\hline Industries & Indices & Property \\
\hline \multirow[t]{6}{*}{ Overall } & GDP output per unit water $\left(¥ / \mathrm{m}^{3}\right)$ & + \\
\hline & Water resources per capita $\left(\mathrm{m}^{3} /\right.$ per capita $)$ & + \\
\hline & Elastic coefficient of total water use (\%) & - \\
\hline & Utilisation rate of water resources development (\%) & - \\
\hline & Water supply satisfaction rate (\%) & + \\
\hline & Comprehensive water use per capita ( $\mathrm{m}^{3} /$ per capita) & - \\
\hline \multirow[t]{6}{*}{ Agricultural } & Irrigation water per unit area $\left(\mathrm{m}^{3} / \mathrm{m}^{2}\right)$ & - \\
\hline & Proportion of agricultural water $(\%)$ & - \\
\hline & Grain output per unit water $\left(\mathrm{kg} / \mathrm{m}^{3}\right)$ & + \\
\hline & Comprehensive utilisation coefficient of irrigation water (\%) & + \\
\hline & Agricultural precipitation efficiency $\left(\mathrm{kg} / \mathrm{m}^{3}\right)$ & + \\
\hline & Water consumption per unit agricultural added value $\left(\mathrm{m}^{3} /\right.$ million $\left.¥\right)$ & - \\
\hline \multirow[t]{4}{*}{ Industrial } & Water consumption per unit industrial added value $\left(\mathrm{m}^{3} /\right.$ million $\left.¥\right)$ & - \\
\hline & Water quota for industrial products $\left(\mathrm{m}^{3} / \mathrm{a}\right)$ & - \\
\hline & Proportion of industrial use of water (\%) & - \\
\hline & Reuse rate of industrial water (\%) & + \\
\hline \multirow[t]{5}{*}{ Domestic } & Urban domestic water consumption per capita $\left(\mathrm{m}^{3} /\right.$ per capita) & - \\
\hline & Rural domestic water consumption per capita $\left(\mathrm{m}^{3} /\right.$ per capita) & - \\
\hline & Reclaimed water-reuse rate in cities and towns (\%) & + \\
\hline & Proportion of domestic water $(\%)$ & - \\
\hline & Leakage rate of urban water supply network (\%) & - \\
\hline \multirow[t]{4}{*}{ Ecological and environmental } & Wastewater discharge treatment rate $(\%)$ & + \\
\hline & Dilution ratio $(\%)$ & - \\
\hline & Qualified rate of water functional areas (\%) & + \\
\hline & Proportion of ecological water (\%) & + \\
\hline
\end{tabular}

to the centre of the universe of discourse. That is, $x$ is closer to the average value of the universe score. The mapping process from $T$ to $U$ conforms to certain regularity with randomness. When $T$ is mapped to $U$ countless times, countless cloud drops will be obtained, which form a cloud map that conforms to a certain rule. It is called the cloud model (Qin et al. 2011).

The cloud model has many forms, such as triangular cloud, trapezoidal cloud and normal cloud. Language qualitative evaluation is usually expressed in the normal cloud (Wang et al. 2014). The normal cloud contains three numerical characteristics:

(1) Expected value Ex is the central value of the universe of language qualitative evaluation. It represents the mathematical expectation of cloud drops distributed over universe $U$.

(2) Entropy En, which expresses the quantifiable granularity of the qualitative evaluation, represents the span of the cloud.

(3) Hyper entropy He, which is the entropy of the entropy En, is the uncertainty measure of En. It reflects the cohesion of the uncertainty measure of all cloud drops in the universe of discourse and represents the thickness of the cloud.

The schematic diagram of the normal cloud is shown in figure 1 . The cloud drops are dense in the middle and scattered on both sides.

The qualitative evaluation of the single index of the BIS is converted into the quantitative score by using the cloud model. The qualitative evaluation is obtained through the questionnaire survey of several experts. The qualitative evaluation of indices is classified into five grades: unimportant, less important, general, important and very important. Each grade corresponds to a universe of discourse, i.e., a score interval (table 2).

According to the critical value of the score interval, three numerical characteristics of the cloud model can be calculated (table 3 ), where He takes the constant.

Based on three numerical characteristics of the cloud model, the required amount of cloud drops can be obtained through the forward normal cloud generator.

The operation steps of the forward normal cloud generator are as follows: 
Step 1: Generate a normally distributed random number $E n^{\prime}{ }_{i}$ with expectation En and standard deviation He.

Step 2: Generate a normally distributed random number $x_{i}$ with expectation Ex and standard deviation $E n^{\prime}{ }_{i}$.

Step 3: Calculate membership degree $y_{i}=\exp \left[-\left(x_{i}-\mathrm{Ex}\right)^{2} / 2 E n_{i}^{\prime 2}\right] . y_{i}$ is the membership degree of the qualitative evaluation $T$. Let $u\left(x_{i}, y_{i}\right)$ be a cloud drop.

Step 4: Repeat steps 1-3 until enough cloud drops are generated.

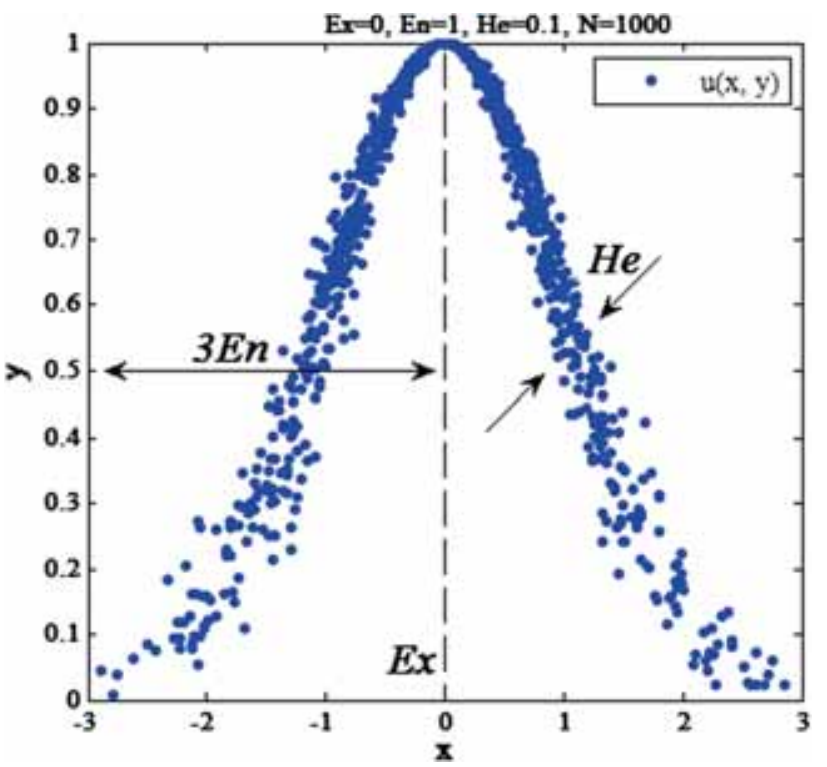

Figure 1. Schematic diagram of the normal cloud.
For one index, $N$ experts are set to evaluate it. The number of experts within the five qualitative evaluation grades is $N_{1}-N_{5}, \quad$ and $N=N_{1}+N_{2}+N_{3}+N_{4}+N_{5}$. That is, there are five universes of discourse $U$ and $N$ cloud drops. The score corresponding to the membership degree of each cloud drop is denoted as $S_{i}$. In each universe of discourse, the required number of cloud drops is obtained by using the forward normal cloud generator. The quantitative score of the index is given by equation (1):

$S=\left(\sum_{i=1}^{N_{1}} S_{i, 1}+\sum_{i=1}^{N_{2}} S_{i, 2}+\sum_{i=1}^{N_{3}} S_{i, 3}+\sum_{i=1}^{N_{4}} S_{i, 4}+\sum_{i=1}^{N_{5}} S_{i, 5}\right) / N$.

The qualitative evaluation of the indices in the BIS is carried out one by one, and the quantitative score is obtained. The indices with higher scores are retained to build the CEIS.

\subsubsection{Compound fuzzy matter element model}

In the matter element analysis, the matter $M$ has a characteristic $C$ and its value is $q$. An ordered triple $R=(M, C, q)$ is the basic element to describe things, which is called matter element (Deng et al. 2015). If the matter $M$ has $m$ characteristics, and the corresponding value $q$ of each characteristic is fuzzy, the $R_{m}$ is named as the $m$ dimension fuzzy matter element. $n$ matters with $m$ dimensions of fuzzy matter element form the compound fuzzy matter element $R_{m n}$. In this paper, a characteristic represents an index of the CEIS. $R_{m n}$ is denoted by equation (2):

Table 2. Index evaluation grade and corresponding score.

\begin{tabular}{lccccc}
\hline Grade & Unimportant & Less important & General & Important & Very important \\
\hline Score interval & $S_{0}-S_{1}$ & $S_{1}-S_{2}$ & $S_{2}-S_{3}$ & $S_{3}-S_{4}$ & $S_{4}-S_{5}$ \\
\hline
\end{tabular}

Table 3. Method for determining numerical characteristics of the cloud model.

\begin{tabular}{|c|c|c|c|}
\hline \multirow[b]{2}{*}{ Natural language } & \multicolumn{3}{|c|}{ Numerical characteristics of the cloud model } \\
\hline & Ex & En & $\mathrm{He}$ \\
\hline Unimportant & $\mathrm{Ex}_{1}=\left(S_{0}+S_{1}\right) / 2$ & $\mathrm{En}_{1}=\left(\mathrm{Ex}_{2}-\mathrm{Ex}_{1}\right) / 3$ & $a$ \\
\hline Less important & $\mathrm{Ex}_{2}=\left(S_{1}+S_{2}\right) / 2$ & $\mathrm{En}_{2}=\left(\mathrm{Ex}_{2}-\mathrm{Ex}_{1}\right) / 3$ & $a$ \\
\hline General & $\mathrm{Ex}_{3}=\left(S_{2}+S_{3}\right) / 2$ & $\mathrm{En}_{3}=\left(\mathrm{Ex}_{3}-\mathrm{Ex}_{2}\right) / 3$ & $a$ \\
\hline Important & $\mathrm{Ex}_{4}=\left(S_{3}+S_{4}\right) / 2$ & $\operatorname{En}_{4}=\left(\mathrm{Ex}_{4}-\mathrm{Ex}_{3}\right) / 3$ & $a$ \\
\hline Very important & $\operatorname{Ex}_{5}=\left(S_{4}+S_{5}\right) / 2$ & $\mathrm{En}_{5}=\left(\mathrm{Ex}_{5}-\mathrm{Ex}_{4}\right) / 3$ & $a$ \\
\hline
\end{tabular}




$$
R_{m n}=\left[\begin{array}{ccccc} 
& M_{1} & M_{2} & \cdots & M_{n} \\
C_{1} & q_{11} & q_{12} & \cdots & q_{1 n} \\
C_{2} & q_{21} & q_{22} & \cdots & q_{2 n} \\
\vdots & \vdots & \vdots & & \vdots \\
C_{m} & q_{m 1} & q_{m 2} & \cdots & q_{m n}
\end{array}\right],
$$

where $C_{i}$ is the $i$ th characteristic $(i=1,2, \ldots, m)$, $M_{j}$ is the $j$ th matter $(j=1,2, \ldots, n)$ and $q_{i j}$ is the fuzzy value of the $j$ th matter on the $i$ th characteristic.

(1) Membership matrix of compound fuzzy matter element: While calculating the membership of each characteristic of compound fuzzy matter element, two properties are considered: the positive correlation and the negative correlation. The calculation process of two properties is given by equations (3) and (4):

$$
\begin{aligned}
& \text { the positive correlation : } u_{i j}=\frac{q_{i j}}{\max q_{i j}}, \\
& \text { the negative correlation : } u_{i j}=\frac{\min q_{i j}}{q_{i j}},
\end{aligned}
$$

where $\max q_{i j}$ and $\min q_{i j}$ are the maximum and minimum of the $i$ th characteristic in all matters, respectively.

The membership matrix can be written as equation (5):

$$
R_{m n}^{\prime}=\left[\begin{array}{ccccc} 
& M_{1} & M_{2} & \cdots & M_{n} \\
C_{1} & u_{11} & u_{12} & \cdots & u_{1 n} \\
C_{2} & u_{21} & u_{22} & \cdots & u_{2 n} \\
\vdots & \vdots & \vdots & & \vdots \\
C_{m} & u_{m 1} & u_{m 2} & \cdots & u_{m n}
\end{array}\right]
$$

(2) Standard fuzzy matter element and different squares of compound fuzzy matter element: The value of the standard fuzzy matter element $R_{m 0}$ is the most satisfactory value of the membership of each characteristic in the membership matrix $R_{m n}^{\prime}$. In this paper, the most satisfactory value was 1 . This is shown in equation (6):

$$
R_{m 0}=\left[\begin{array}{ccccc} 
& C_{1} & C_{2} & \cdots & C_{m} \\
M_{0} & 1 & 1 & \cdots & 1
\end{array}\right]
$$

Let $\Delta_{i j}$ denote the different squares between standard fuzzy matter element $R_{m 0}$ and the membership matrix $R_{m n}^{\prime}, \Delta_{i j}=\left(1-u_{i j}\right)^{2}(i=1,2$, $\ldots, m ; j=1,2, \ldots, n)$. The different squares of compound fuzzy matter element can be written as equation (7):

$$
R_{\Delta}=\left[\begin{array}{ccccc} 
& M_{1} & M_{2} & \cdots & M_{n} \\
C_{1} & \Delta_{11} & \Delta_{12} & \cdots & \Delta_{1 n} \\
C_{2} & \Delta_{21} & \Delta_{22} & \cdots & \Delta_{2 n} \\
\vdots & \vdots & \vdots & & \vdots \\
C_{m} & \Delta_{m 1} & \Delta_{m 2} & \cdots & \Delta_{m n}
\end{array}\right]
$$

(3) Euclid approach degree: The approach degree describes the degree of proximity between the evaluated scheme and the standard scheme of each matter. The larger the approach degree is, the better the degree of proximity is (Zhang et al. 2018b). In this paper, the specific evaluation significance was taken into account. So, the Euclid approach degree was used to analyse the matter. This is shown in equation (8):

$$
\rho H_{j}=1-\left(\sum_{i=1}^{m} w_{i} \Delta_{i j}\right),
$$

where $\rho H_{j}$ is the Euclid approach degree of the $j$ th matter, which is a comprehensive indicator of the $j$ th matter. $w_{i}$ is the weight of the ith characteristic. In this paper, the entropy model was introduced to determine the weight of each index.

Based on equation (8), the Euclid approach degree matrix of compound fuzzy matter element is denoted by equation (9):

$$
R_{\rho H}=\left[\begin{array}{ccccc} 
& M_{1} & M_{2} & \cdots & M_{n} \\
\rho H_{j} & \rho H_{1} & \rho H_{2} & \cdots & \rho H_{n}
\end{array}\right]^{\mathrm{T}} .
$$

\subsubsection{Entropy model}

According to the information provided by each characteristic, the weight of each characteristic is calculated with the entropy model to avoid subjectivity (Pan et al. 2015). The objective weight of each characteristic is determined by the following steps.

(1) The judgment matrix $Q=\left(q_{i j}\right)_{m \times s}$ is processed by equations (10) and (11) to convert into the relative membership matrix $R=\left(r_{i j}\right)_{m \times s}$ according to the property of each characteristic.

the positive correlation : $\quad r_{i j}=\frac{q_{i j}-\left(q_{i j}\right)_{\min }}{\left(q_{i j}\right)_{\max }-\left(q_{i j}\right)_{\min }}$,

the negative correlation : $\quad r_{i j}=\frac{\left(q_{i j}\right)_{\max }-q_{i j}}{\left(q_{i j}\right)_{\max }-\left(q_{i j}\right)_{\min }}$, 
where $\left(q_{i j}\right)_{\max }$ and $\left(q_{i j}\right)_{\min }(i=1,2, \ldots, m ; j=$ $1,2, \ldots, s)$ are the maximum and minimum of the $i$ th characteristic in all samples, respectively. $s$ is the total number of samples.

(2) The proportion $f_{i j}$ of the jth sample's characteristic value of $i$ occupied in the total value of the $i$ th characteristic is defined by equation (12):

$$
f_{i j}=\frac{1+r_{i j}}{\sum_{j=1}^{s}\left(1+r_{i j}\right)} .
$$

(3) Calculate the entropy $H_{i}$ of the ith characteristic by equation (13):

$$
H_{i}=-\frac{\sum_{j=1}^{s} f_{i j} \ln f_{i j}}{\ln s} .
$$

(4) Determine the $w_{i}$ of the $i$ th characteristic by equation (14):

$$
w_{i}=\frac{1-H_{i}}{\sum_{i=1}^{m}\left(1-H_{i}\right)} .
$$

Obviously, $0 \leq w_{i} \leq 1, \sum_{i=1}^{m} w_{i}=1$.

\section{Study area and data}

The HRB is in eastern China, between the Yangtze river basin and the Yellow river basin. It is located at $111^{\circ} 55^{\prime}-121^{\circ} 25^{\prime} \mathrm{E}$ and $30^{\circ} 55^{\prime}-36^{\circ} 36^{\prime} \mathrm{N}$, with the drainage area being $270,000 \mathrm{~km}^{2}$. The Huai river drains five provinces (Henan, Anhui, Jiangsu, Shandong and Hubei) with a full length $1000 \mathrm{~km}$ of main stream. Shaying river and Wo river are the two main tributaries. The annual and inter-annual fluctuation of the total water resources in the HRB is large, but the annual water consumption presents a parabola form with time. The HRB is an important transportation hub of China. The industrial development is dominated by the heavy industry with coal and electric power and the light industry with food and textiles. The water demand is relatively large during industrial production. Besides, the HRB is a very important grain production base in China. With the increase of population and urbanisation, the agricultural output and the quality of life need to be continuously improved, both of which need the support of water resources. At the same time, the contradiction between the human water use and the ecological water use is increasing gradually. The problem of water shortage is becoming more and more serious, which affects the development of the social economy and the health of the water ecological environment in the river basin. Therefore, improving the WUE is an important way to solve the water problem in the basin. In addition, the area occupied by the Hubei region is too small to be considered in the evaluation scope. The map of the HRB is shown in figure 2.

In this study, the evaluation of the WUE during the time period of 2007-2016 is considered in the HRB. The index data of each industry used were collected from the Water Resources Bulletin of the HRB and the Provincial Statistical Yearbook of Henan, Jiangsu, Anhui and Shandong. Hence, the original data selected in this paper is authentic and operable.

\section{Results and discussion}

\subsection{Structure of the CEIS of WUE}

The cloud model was applied to select some indices suitable for the HRB from the BIS. In the process of determining the numerical characteristics, five score intervals were set. The full score was 100 . We let each interval have the same spacing (table 4). Five score intervals have been able to reflect the diversity of qualitative evaluation. Because of multiple indices, the scores of the indices are more varied through the percentage grading system, which avoids the same scores. It is convenient to sort and distinguish indices. Then, Ex and En were calculated according to the critical value of the score interval. He represents the thickness of the cloud. The larger the He is, the more discrete the cloud drops are. It indicates that the stability of the quantitative score corresponding to the qualitative evaluation is bad. That is, in the same qualitative evaluation, the possibility of generating different scores becomes bigger. In this paper, the number of experts surveyed was 50 . The cloud type that is too discrete is not needed, because the number of experts is not too large in each qualitative evaluation interval. Therefore, we adopted the empirical value of 0.05 ( $\mathrm{Hu}$ et al. 2007; Li et al. 2009; Chen et al. 2015). The result of the three numerical characteristics is shown in table 5 .

In this study, 50 qualitative evaluation results of each index were obtained through the questionnaire survey of 50 experts (table 6). Taking the gross domestic product (GDP) output per unit water, e.g., the calculation process of the index 


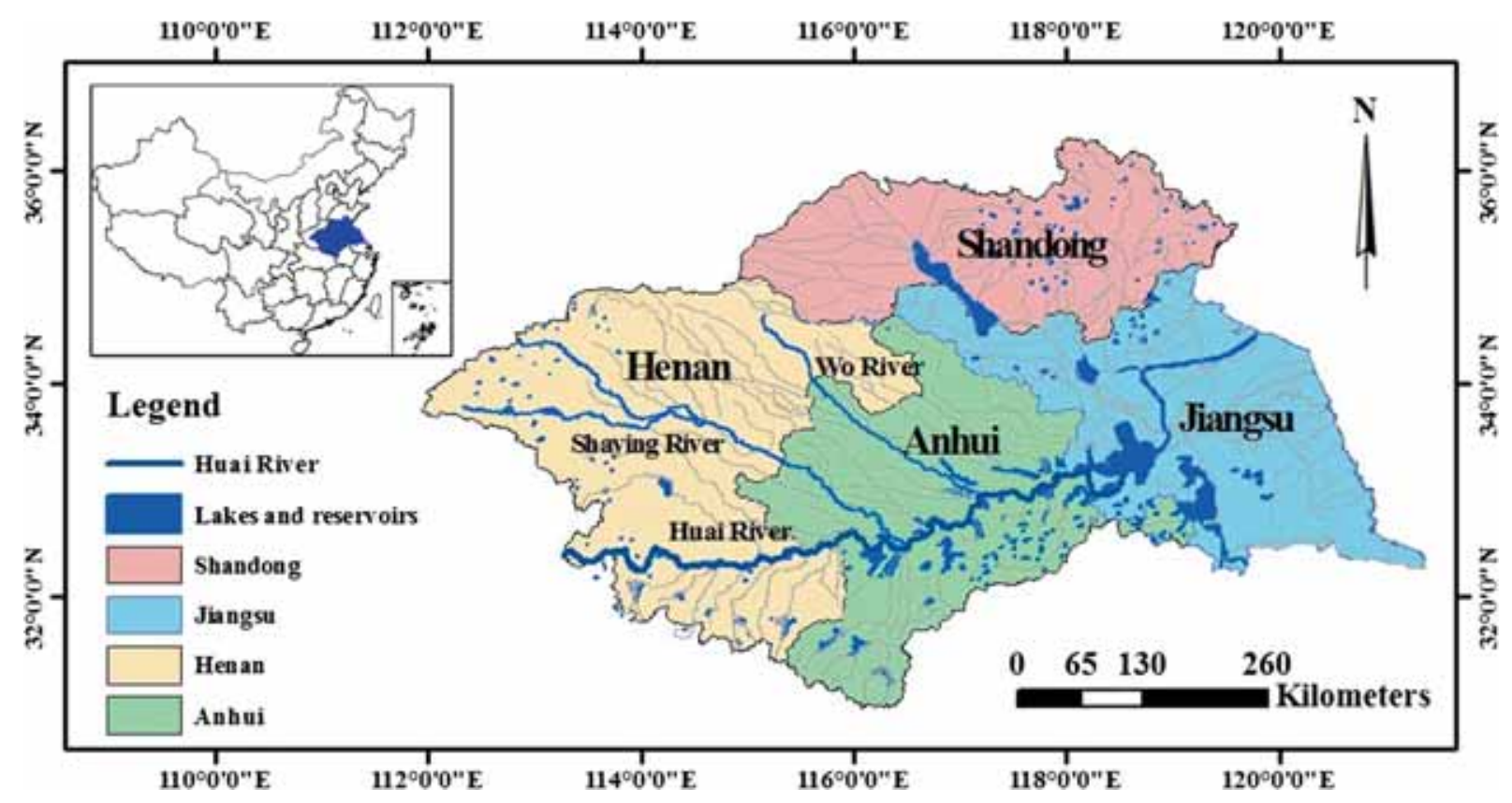

Figure 2. Map of the HRB.

Table 4. Score interval of each grade.

\begin{tabular}{lccccc}
\hline Grade & Unimportant & Less important & General & Important & Very important \\
\hline Score interval & $0-20$ & $20-40$ & $40-60$ & $60-80$ & $80-100$ \\
\hline
\end{tabular}

Table 5. Numerical characteristics of the cloud model.

\begin{tabular}{lccc}
\hline & \multicolumn{3}{c}{$\begin{array}{c}\text { Numerical characteristics of the cloud } \\
\text { model }\end{array}$} \\
\cline { 2 - 4 } Natural language & $\mathrm{Ex}$ & $\mathrm{En}$ & $\mathrm{He}$ \\
\hline Unimportant & 10 & 6.67 & 0.05 \\
Less important & 30 & 6.67 & 0.05 \\
General & 50 & 6.67 & 0.05 \\
Important & 70 & 6.67 & 0.05 \\
Very important & 90 & 6.67 & 0.05 \\
\hline
\end{tabular}

score was explained. The number of experts who considered that the index was unimportant, less important, general, important and very important was $1,3,7,21$ and 18, respectively. In each interval, the forward normal cloud generator was driven to generate enough cloud drops corresponding to the number of experts. The cloud map of each interval is shown in figure 3 . Then equation (1) was used to summarise the scores of 50 cloud drops, and the quantitative score of the GDP output per unit water was 70.7. Last of all, the quantitative score of each index in the BIS was calculated by the same method. The result is shown in table 6 .

The top 10 indices with the highest scores were selected to construct the CEIS, as shown in table 7 .

It is necessary to grade the evaluation standard of indices based on the combined model. According to expert opinion, the evaluation standard could be divided into three levels: good, medium and poor, which are represented by symbols I, II and III, respectively. The level I represents the planning level in China. By 2020, the system of rational allocation and efficient utilisation of water resources will be basically completed, which is suitable for the requirements of economic and social development, and it can make a significant improvement to WUE. Most index standards of level I refer to the data of the 13th 5-year plan of the HRB, which is a high standard of WUE by government departments. Level II mainly refers to the general level and assessment standard at the present stage. The values in level II are the average of each index of the HRB (10 years from 2007 to 2016). Level III refers to the calculated values of WUE of the HRB during the historical 
Table 6. Evaluation result and score of each index in the BIS.

\begin{tabular}{|c|c|c|c|c|c|c|}
\hline \multirow[b]{2}{*}{ Indices } & \multicolumn{5}{|c|}{ Experts of each interval } & \multirow[b]{2}{*}{ Score } \\
\hline & $0-20$ & $20-40$ & $40-60$ & $60-80$ & $80-100$ & \\
\hline GDP output per unit water & 1 & 3 & 7 & 21 & 18 & 70.7 \\
\hline Water resources per capita & 6 & 9 & 23 & 10 & 2 & 46.7 \\
\hline Elastic coefficient of total water use & 8 & 12 & 19 & 11 & 0 & 44.0 \\
\hline Utilisation rate of water resources development & 2 & 3 & 20 & 12 & 13 & 63.1 \\
\hline Water supply satisfaction rate & 11 & 16 & 21 & 2 & 0 & 34.9 \\
\hline Comprehensive water use per capita & 5 & 7 & 20 & 17 & 1 & 52.0 \\
\hline Irrigation water per unit area & 1 & 2 & 3 & 26 & 18 & 72.7 \\
\hline Proportion of agricultural water & 14 & 11 & 21 & 3 & 1 & 37.0 \\
\hline Grain output per unit water & 0 & 9 & 12 & 21 & 8 & 59.8 \\
\hline Comprehensive utilisation coefficient of irrigation water & 17 & 12 & 10 & 11 & 0 & 35.6 \\
\hline Agricultural precipitation efficiency & 22 & 17 & 9 & 2 & 0 & 25.3 \\
\hline Water consumption per unit agricultural added value & 9 & 19 & 16 & 6 & 0 & 38.0 \\
\hline Water consumption per unit industrial added value & 0 & 1 & 2 & 18 & 29 & 79.5 \\
\hline Water quotas for industrial products & 16 & 23 & 4 & 6 & 1 & 32.0 \\
\hline Proportion of industrial use of water & 5 & 11 & 26 & 3 & 5 & 46.7 \\
\hline Reuse rate of industrial water & 3 & 8 & 33 & 6 & 0 & 47.5 \\
\hline Urban domestic water consumption per capita & 0 & 3 & 14 & 29 & 4 & 63.4 \\
\hline Rural domestic water consumption per capita & 2 & 3 & 12 & 31 & 2 & 60.5 \\
\hline Reclaimed water-reuse rate in cities and towns & 6 & 22 & 16 & 4 & 2 & 40.7 \\
\hline Proportion of domestic water & 18 & 22 & 7 & 3 & 0 & 29.2 \\
\hline Leakage rate of urban water supply network & 5 & 26 & 2 & 15 & 2 & 43.0 \\
\hline Wastewater discharge treatment rate & 14 & 21 & 15 & 0 & 0 & 29.0 \\
\hline Dilution ratio & 2 & 11 & 4 & 27 & 6 & 58.4 \\
\hline Qualified rate of water functional areas & 0 & 5 & 2 & 22 & 21 & 73.9 \\
\hline Proportion of ecological water outside rivers & 0 & 1 & 17 & 19 & 13 & 67.1 \\
\hline
\end{tabular}

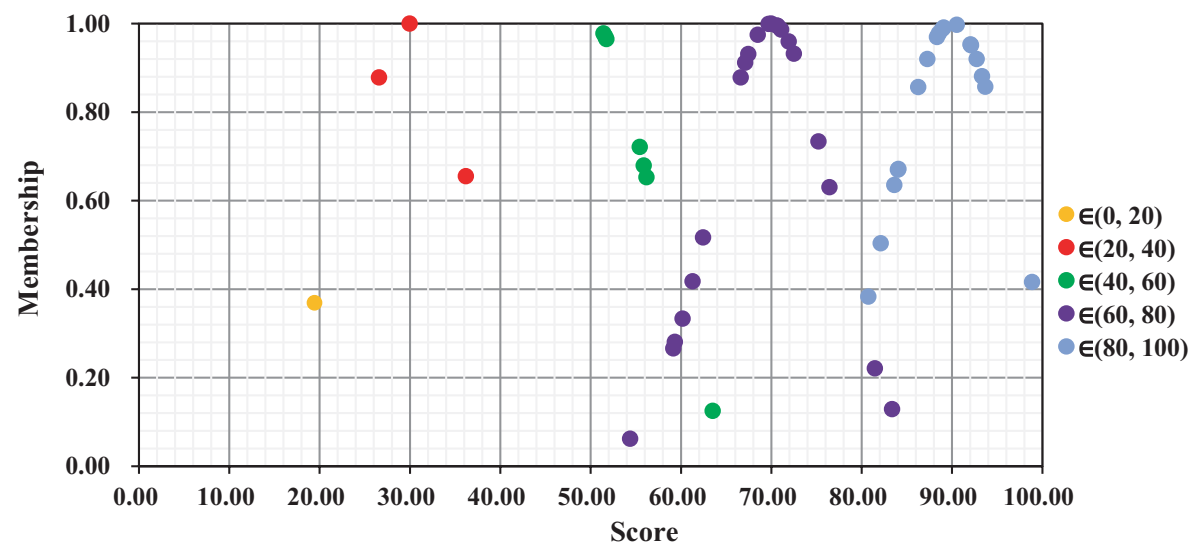

Figure 3. Cloud map of the GDP output per unit water.

period 2007-2010. The low standard of indices is selected from 2007 to 2010 according to the property of each index. The positive correlation index selects the minimum value in a certain year during the period, while the negative correlation index selects the maximum value. People developed economy at the expense of the environment and failed to realise the value of water. The results are given in table 8 .

\subsection{Index weight of the CEIS}

The entropy model was used to calculate the weight of each index in the CEIS. The input data 
Table 7. Result of indices selected.

\begin{tabular}{|c|c|c|c|}
\hline$\underline{\text { Indices }}$ & Units & Property & Codes \\
\hline GDP output per unit water & $¥ / \mathrm{m}^{3}$ & + & $O_{1}$ \\
\hline Utilisation rate of water resources development & $\%$ & - & $\mathrm{O}_{2}$ \\
\hline Irrigation water per unit area & $\mathrm{m}^{3} / \mathrm{m}^{2}$ & - & $A_{1}$ \\
\hline Grain output per unit water & $\mathrm{kg} / \mathrm{m}^{3}$ & + & $A_{2}$ \\
\hline Water consumption per unit industrial added value & $\mathrm{m}^{3} /$ million $¥$ & - & $I_{1}$ \\
\hline Urban domestic water consumption per capita & $\mathrm{m}^{3} /$ per capita & - & $D_{1}$ \\
\hline Rural domestic water consumption per capita & $\mathrm{m}^{3} /$ per capita & - & $D_{2}$ \\
\hline Proportion of ecological water outside rivers & $\%$ & + & $E_{1}$ \\
\hline Qualified rate of water functional areas & $\%$ & + & $E_{2}$ \\
\hline Dilution ratio & $\%$ & - & $E_{3}$ \\
\hline
\end{tabular}

Table 8. Evaluation standard of the CEIS.

\begin{tabular}{llcl}
\hline & \multicolumn{3}{c}{ Levels } \\
\cline { 2 - 4 } Indices & $\mathrm{I}$ & $\mathrm{II}$ & $\mathrm{III}$ \\
\hline$O_{1}\left(¥ / \mathrm{m}^{3}\right)$ & $\geq 156$ & $\geq 84$ & $\geq 30$ \\
$O_{2}(\%)$ & $\leq 15$ & $\leq 40$ & $\leq 60$ \\
$A_{1}\left(\mathrm{~m}^{3} / \mathrm{m}^{2}\right)$ & $\leq 0.3$ & $\leq 0.4$ & $\leq 0.5$ \\
$A_{2}\left(\mathrm{~kg} / \mathrm{m}^{3}\right)$ & $\geq 7.5$ & $\geq 5.5$ & $\geq 3.0$ \\
$I_{1}\left(\mathrm{~m}^{3} / \mathrm{million}\right)$ & $\leq 23$ & $\leq 48$ & $\leq 85$ \\
$D_{1}\left(\mathrm{~m}^{3} /\right.$ per capita $)$ & $\leq 35$ & $\leq 42$ & $\leq 46$ \\
$D_{2}\left(\mathrm{~m}^{3} /\right.$ per capita $)$ & $\leq 22$ & $\leq 26$ & $\leq 32$ \\
$E_{1}(\%)$ & $\geq 3.5$ & $\geq 1.5$ & $\geq 0.4$ \\
$E_{2}(\%)$ & $\geq 80$ & $\geq 53$ & $\geq 36$ \\
$E_{3}(\%)$ & $\leq 2.6$ & $\leq 5.3$ & $\leq 8$ \\
\hline
\end{tabular}

for the entropy model were the values of the indices of 50 samples (average level and four regions of the HRB from 2007 to 2016), namely, matrix $Q=\left(q_{i j}\right)_{m \times s}(m=10, s=50)$. Using equations (10)-(14), the weight of each index was obtained (figure 4).

From figure 4, the four indices $O_{1}, A_{2}, D_{2}$ and $E_{1}$ had larger weights, which had a great influence on the comprehensive indictors of WUE in the HRB and its four regions. Water used for agricultural irrigation accounts for more than $60 \%$ of the total water consumption in the HRB. So the overall WUE is most affected by agricultural WUE and the level of economic development. Besides, the HRB has the highest population density among the seven major river basins of China, so domestic WUE greatly impacts the overall WUE. At the same time, water ecological environment is closely related to economic development and people's life, so environmental WUE also has a great effect on the overall WUE.

\subsection{Comprehensive indicators of WUE}

The compound fuzzy matter element model was used to calculate the comprehensive indictors of WUE. The input data for the compound fuzzy matter element model included the values of the indices of 50 samples and the 3 boundary conditions of different evaluation standards (table 8), which showed as the matrix $R_{m n}(m=10, n=53)$. According to equations (2)-(9), the comprehensive boundaries (table 9) and the comprehensive indicators (figure 5) of WUE were obtained. Among

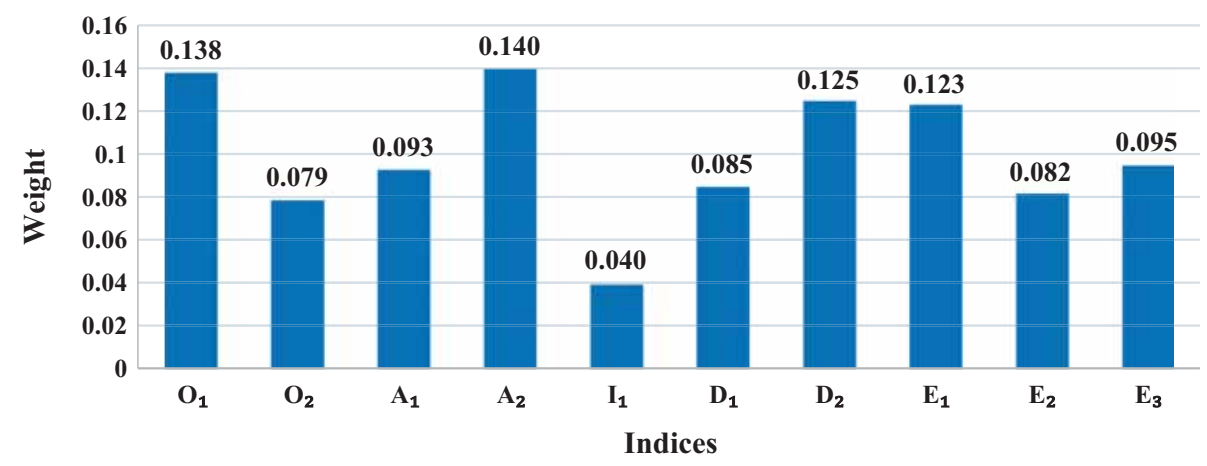

Figure 4. Weight of each index of the CEIS. 
them, the weight of each index involved in equation (8) was calculated with the entropy model.

From figure 5, the comprehensive indicators of WUE of the HRB and its four regions showed an upward trend from 2007 to 2016 on the whole. It shows that more and more attention has been paid to water resources protection and efficient utilisation, and more and more efforts have been made to protect water environment. Therefore, WUE of the $\mathrm{HRB}$ is improving year by year. The change is consistent with the development trend of international WUE. With the development of economy and the growth of population, water shortage is a serious problem, which is caused by limitations of water resources in time and space. The improvement of WUE is a wise way to solve the problem of water shortage. The United Nations has repeatedly warned that the world is facing a water crisis (Kujinga et al. 2014; Simonovic 2017). To cope with water problems, the World Water Week Forum held by the Stockholm International Water Institute had proved the development direction of water management. That is, guaranteeing the sustainable use of water resources to support the economic and social sustainable development (Surhone et al. 2010). It is observed from the calculation that global WUE has greatly increased, with water consumption per USD 10,000 of GDP

Table 9. Comprehensive boundaries of WUE.

\begin{tabular}{lccc}
\hline Grade & I & II & III \\
\hline Comprehensive boundaries & $\geq 0.652$ & $\geq 0.425$ & $\geq 0.275$ \\
\hline
\end{tabular}

decreased from $805 \mathrm{~m}^{3}$ in 2005 to $527 \mathrm{~m}^{3}$ in 2016, which is a decrease by $34.57 \%$ (Yan et al. 2018; FAO AQUASTAT).

From figure 6 , there is a big difference in WUE between different regions of the same river basin. On the whole, WUE of provinces gradually increases from the east to the west. The central cities enjoy a flat terrain, convenient transportation and rapid economic development, which are helpful in introducing improved water-saving technologies in some industries. These will effectively improve WUE of central cities. Thus, WUE of the whole area is driven by the central cities. Henan province is a major agricultural province in China. Its agricultural water-saving technology is advanced, which results in improved agricultural WUE. The improvement of overall WUE can be driven by agricultural WUE (figure 7). The approach of driving overall WUE through an efficient water industry has been adopted in other areas of the world, such as Israel (Tal 2016) and Alberta (Ali and Klein 2014). To maintain economic development, the integrity of water ecosystem is often neglected, which aggravates environmental pollution and ecological destruction and weakens the renewability and sustainability of water resources. Jiangsu region is affected by ecological degradation and environmental pollution, because the ecological water use is severely compressed (figure 8). WUE is also a constraining factor which needs to be solved globally. Water pollution in India, Nigeria and Freetown severely restricts the sustainable development of water

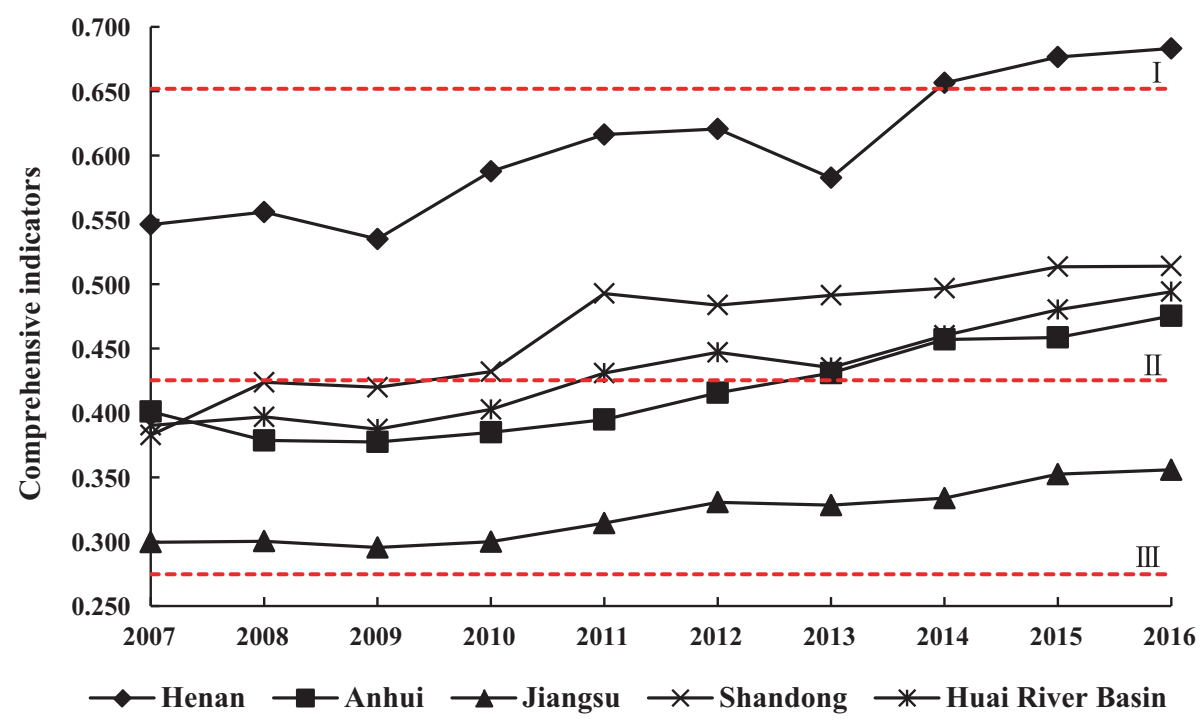

Figure 5. Comprehensive indicators of WUE. 

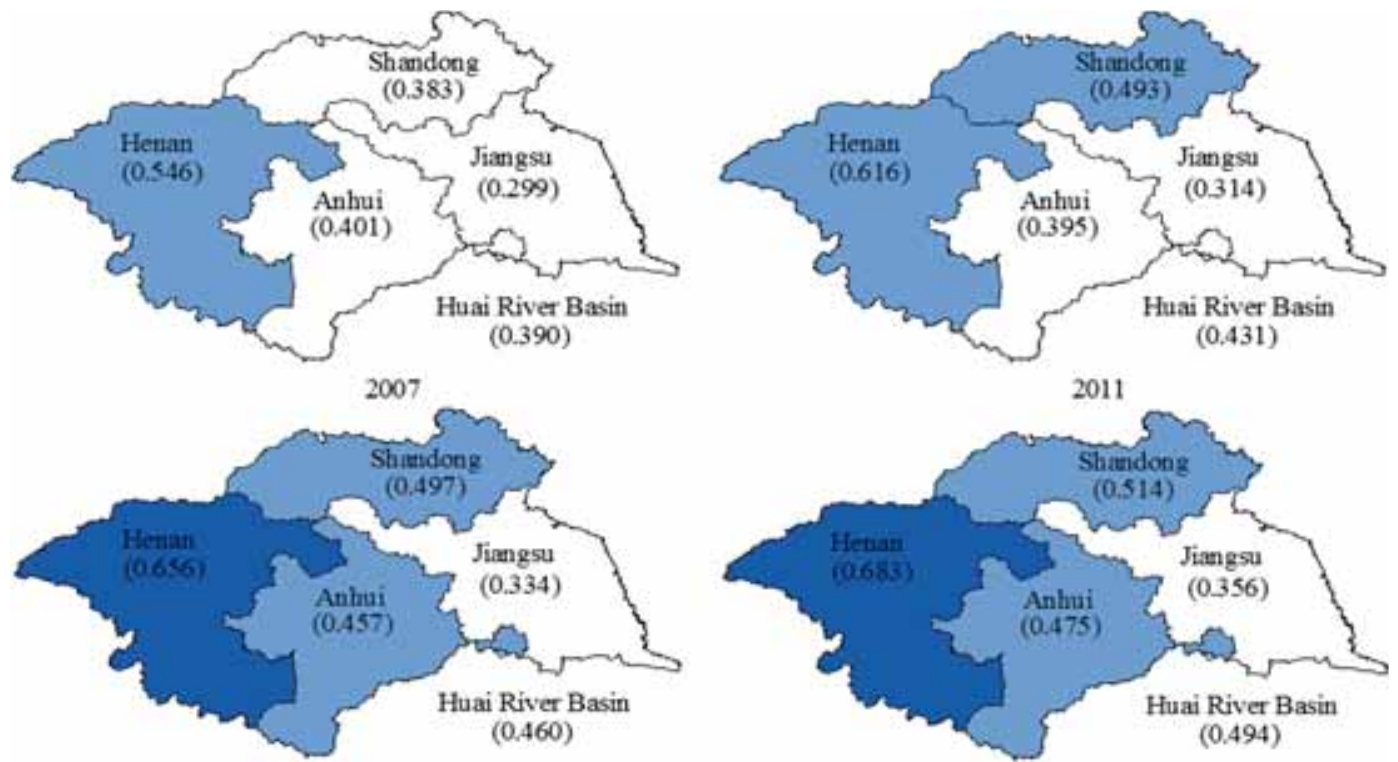

2014

2016

Figure 6. Spatial comprehensive indicators of the provinces in representative years.

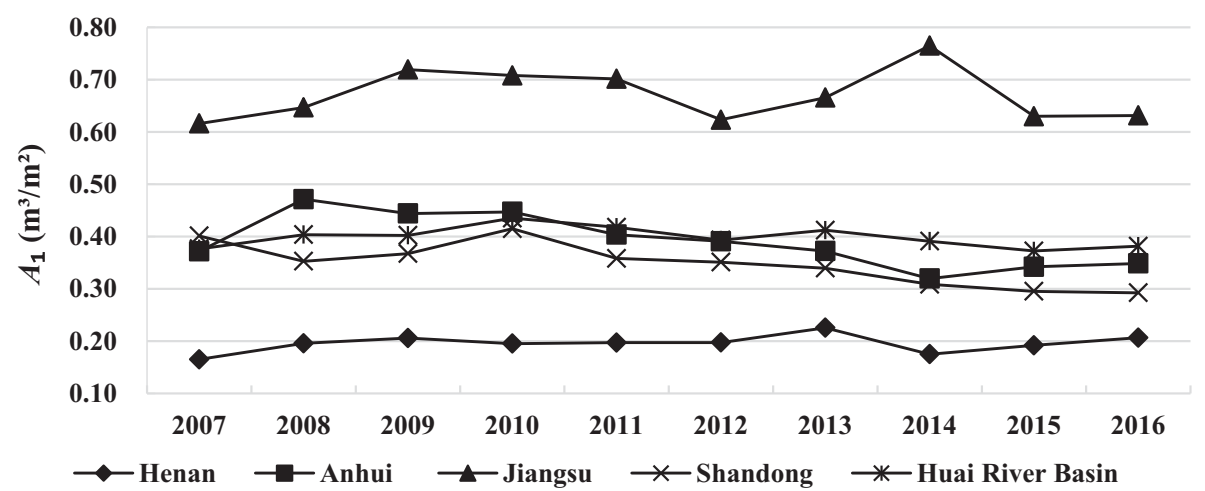

(a) The change trends of the $A_{1}$ index of the HRB and its regions from 2007 to 2016.

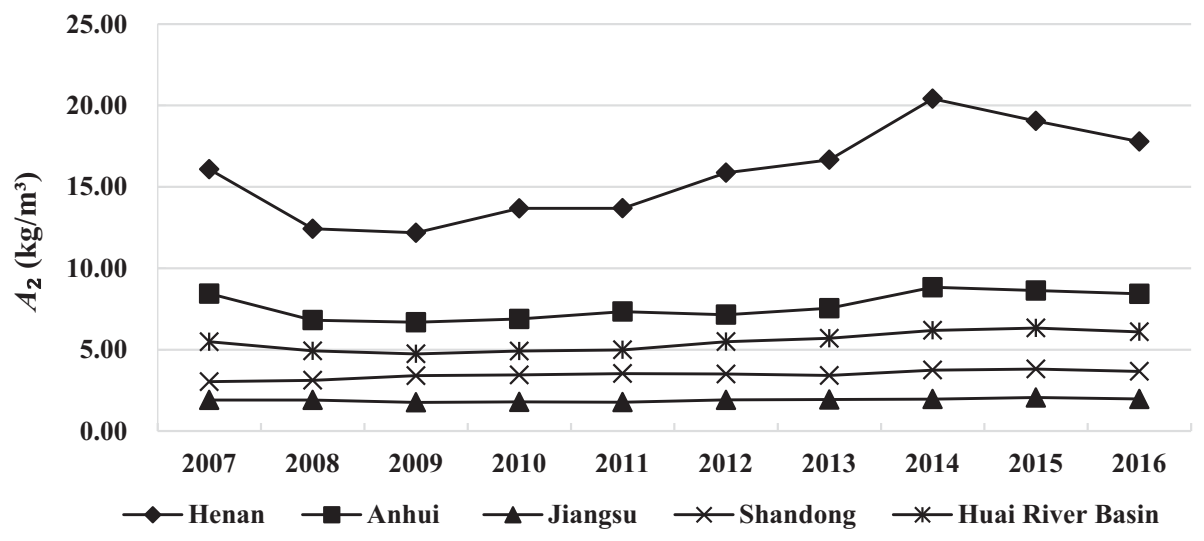

(b) The change trends of the $A_{2}$ index of the HRB and its regions from 2007 to 2016.

Figure 7. Change trends of agricultural indices of the HRB and its regions from 2007 to 2016: (a) the $A_{1}$ index and (b) the $A_{2}$ index. 


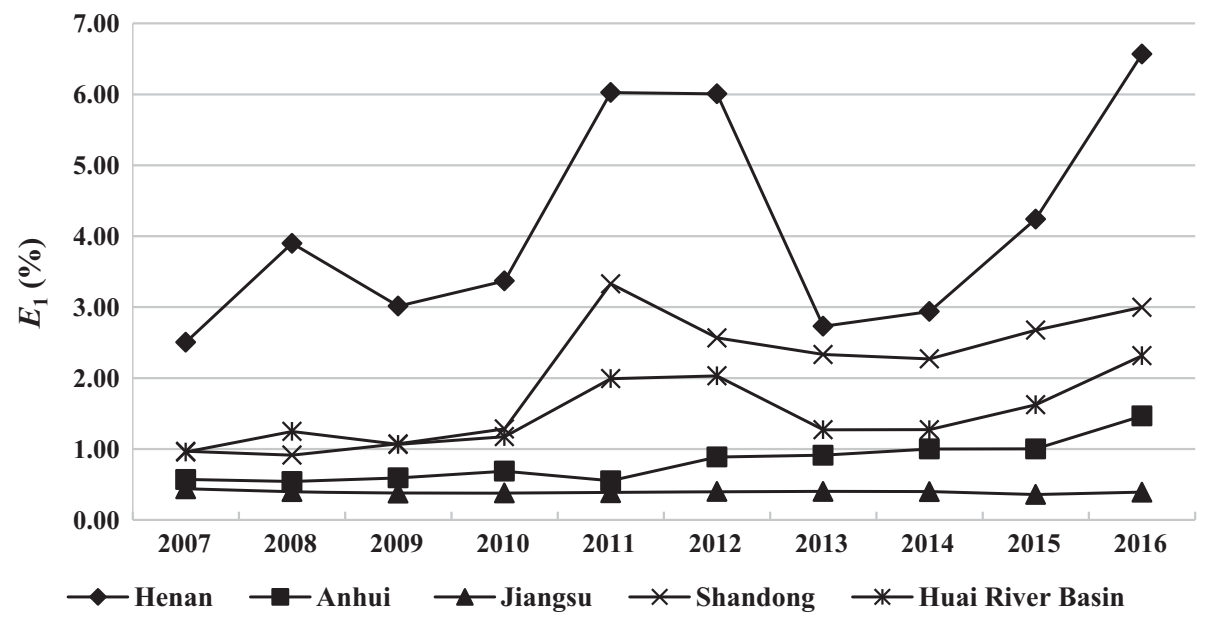

Figure 8. Change trends of the $E_{1}$ index of the HRB and its provinces from 2007 to 2016.

resources (Kallon 2008; Adedeji and Ako 2011; Khan et al. 2016). International reports have mentioned that protecting water ecological environment is to support the sustainable development of water resources (SIWI 2010; UN 2015a). Therefore, with the improvement of social economy, attention should be paid to ecological and environmental protection. We must coordinate the usage of water in producing, living and maintaining ecological balance. In future research, achieving the sustainable utilisation of water resources is still likely the most important task of water resources management.

It can be seen that the improvement of WUE must be comprehensive. The evaluation scope of the study covers production, living and maintaining the ecological environment. Only by fully understanding the current status of WUE we can make targeted improvements. In view of the above problems, several suggestions were put forward. Firstly, the rationality and effectiveness of the optimal allocation of water resources should be improved. The theoretical research on the optimal allocation of water resources should be emphasised. We must actively encourage universities and research institutes to cooperate with production departments, so as to carry out research on the optimal allocation of water resources. Meanwhile, the combination of theory and practice should be valued. According to the characteristic of each region, we formulate the corresponding allocation plan of water resources. Secondly, water resources management system and water-saving measures must be perfected. It is essential to analyse the emphasis and vulnerabilities of water use in each industry, scientifically adjust the structure of economic industry and water use, and constantly improve water-saving projects and technical systems. At the same time, we must accelerate technological innovation and popularise water-saving facilities. Thirdly, both the development and utilisation of water resources and the protection of the ecological environment should be taken into account. We must strictly control the total amount of water withdrawal, and implement the responsibility and appraisal institution. Pollutants must be reduced from the source, and the total discharge of water pollutants must be strictly controlled. We will integrate water ecological environment protection into the economic system and establish a strong water ecological environment management mechanism.

\section{Conclusions}

In this study, a cloud-compound fuzzy matter element-entropy combined model was constructed to comprehensively evaluate WUE. The combined model was applied to the HRB. The cloud model was used to select some indices and build the CEIS. The CEIS includes the overall, agricultural, industrial, domestic and environmental indices. The compound fuzzy matter element model was used to calculate comprehensive indicators of WUE of the HRB and its regions. The comprehensive boundaries of WUE also were determined. The entropy model was used to calculate the weight value of each index. The evaluation result can intuitively reflect the temporal and spatial variation. From 2007 to 2016, the WUE of the HRB had an upward trend on the whole, which was 
inseparable from the high attention paid by the international and national governments to water resources. However, the WUE among different regions was obviously different. This is a common international problem. It is an effective means of improving the overall WUE through the water industry's high efficiency of utilisation. But environmental pollution and ecological destruction would seriously affect the renewability and sustainability of water resources. Besides, some suggestions are proposed to improve WUE. The results and discussion of this study can provide decision-making reference for water resources management departments in the HRB and the combined model can be extended to other regions.

\section{Acknowledgements}

The authors would like to express their gratitude to everyone who provided assistance towards this study. This study was financially supported by the National Natural Science Foundation of China (Grant Nos. 51879241, 51809239 and 51739009).

\section{References}

Adedeji A A and Ako R T 2011 Towards achieving the United Nations' millennium development goals: The imperative of reforming water pollution control and waste management laws in Nigeria; Desalination 248(1) 642-649.

Ali M K and Klein K K 2014 Water use efficiency and productivity of the irrigation districts in Southern Alberta; Water Resour. Manag. 28(10) 2751-2766.

Amiri V, Rezaei M and Sohrabi N 2014 Groundwater quality assessment using entropy weighted water quality index (EWQI) in Lenjanat, Iran; Env. Earth Sci. 72(9) 3479-3490.

Azad M A and Ancev T 2014 Measuring environmental efficiency of agricultural water use: A Luenberger environmental indicator; J. Env. Manag. 145(145C) 314-320.

Chen J, Zhang F and Yang C et al. 2017 Factor and trend analysis of total-loss marine casualty using a fuzzy matter element method; Int. J. Disast. Risk Re. 24 383-390.

Chen Y J, Liu D W, Zhu D Y, Zheng R K, Feng B J and Ni Y 2015 Comprehensive safety evaluation of ship ammunition depot based on cloud model; J. Saf. Sci. Technol. 2015-2 138-144.

Christiansen B 2009 Is the atmosphere interesting? A projection pursuit study of the circulation in the Northern Hemisphere winter; J. Clim. 22(22) 1239-1254.

Deng X, Xu Y, Han L, Yu Z, Yang M and Pan G 2015 Assessment of river health based on an improved entropybased fuzzy matter-element model in the Taihu plain, China; Ecol. Indic. 57 85-95.

Dong L, Wang P and Yan F 2016 Damage forecasting based on multi-factor fuzzy time series and cloud model; J. Intell. Manuf. 2019(2) 1-18.
FAO AQUASTAT 2005-2016 Rome, Food and Agriculture Organization of the United Nations (FAO; http://www.fao. $\mathrm{org} / \mathrm{nr} /$ water/aquastat/main/index.stm).

Fujii H, Managi S and Kaneko S 2012 A water resource efficiency analysis of the Chinese industrial sector; Env. Econ. 3(3) 82-92.

Guan X J, Liang S X and Meng Y 2016 Evaluation of water resources comprehensive utilization efficiency in Yellow River basin; Water Sci. Tech.-Water Sup. 16(6).

Guo Z C and Fu Z X 2010 Current situation of energy consumption and measures taken for energy saving in the iron and steel industry in China; Energy 35(11) 4356-4360.

Hu S Y, Li D R, Liu Y L and Li D Y 2007 Mining weights of land evaluation factors based on cloud model and correlation analysis; Geo-Spatial Inf. Sci. 10(3) 218-222.

Kallon S B 2008 Pollution and sanitation problems as setbacks to sustainable water resources management in Freetown; $J$. Env. Health 71(5) 34-37.

Karimi P, Molden D, Bastiaanssen W and Cai X 2012 Water accounting to assess use and productivity of water-evolution of the concept and new frontiers; In: Water accounting: International approaches to policy and decision-making (eds) Chalmers K and Godfrey J, Chapter 4, Edgar Elger, Cheltenham, UK, pp. 76-88.

Keshavarzi A R, Sharifzadeh M, Kamgar Haghighi A A, Amin S, Sh K and Bamdad A 2006 Rural domestic water consumption behavior: A case study in Ramjerd area, Fars province, I.R. Iran; Water Res. 40(6) 1173-1178.

Khan M Y A, Khan B and Chakrapani G J 2016 Assessment of spatial variations in water quality of Garra River at Shahjahanpur, Ganga Basin, India; Arab. J. Geosci. 9(8) 516.

Kujinga K, Vanderpost C, Mmopelwa G and Wolski P 2014 An analysis of factors contributing to household water security problems and threats in different settlement categories of Ngamiland, Botswana; Phys. Chem. Earth 67-69(2) 187-201.

Lei M T 2017 Application of SFLA-PP model to comprehensive evaluation of utilization efficiency of regional water resources; J. Yangtze River Sci. Res. Inst. 34(11) 27-32.

Li D, Liu C and Gan W 2009 A new cognitive model: Cloud model; Int. J. Intell. Syst. 24(3) 357-375.

Lu S, Bao H and Pan H 2016 Urban water security evaluation based on similarity measure model of Vague sets; Int. J. Hydrog. Energy 41(35) 15944-15950.

Maruyama T, Kawachi T and Singh V P 2005 Entropy-based assessment and clustering of potential water resources availability; J. Hydrol. 309(1) 104-113.

Moore A D, Robertson M J and Routley R 2011 Evaluation of the water use efficiency of alternative farm practices at a range of spatial and temporal scales: A conceptual framework and a modelling approach; Agr. Syst. 104(2) 162-174.

Pan G, Xu Y, Yu Z, Song S and Zhang Y 2015 Analysis of river health variation under the background of urbanization based on entropy weight and matter-element model: A case study in Huzhou city in the Yangtze river delta, China; Env. Res. 139 31-35.

Playan E and Mateos L 2006 Modernization and optimization of irrigation systems to increase water productivity; Agri. Water Manag. 79(1) 100-116.

Qin K, Liu F, Liu F and Li D 2011 Image segmentation based on histogram analysis utilizing the cloud model; Comput. Math. Appl. 62(7) 2824-2833. 
Orencio P M and Fujii M 2013 A localized disaster-resilience index to assess coastal communities based on an analytic hierarchy process (AHP); Int. J. Disast. Risk Re. 3 62-75.

Sadras V O, Grassini P and Steduto P 2012 Status of water use efficiency of main crops; SOLAW Background Thematic Report TR07. United Nations FAO, Rome, Italy.

Simonovic S P 2017 Bringing future climatic change into water resources management practice today; Water Resour. Manag. 31(10) 2933-2950.

SIWI 2010 World Water Week 2010: Responding to GlobalChanges: The Water Quality Challenge-Prevention, Wise Use and Abatement; Stockholm International Water Institute.

Surhone L M, Tennoe M T and Henssonow S F 2010 World water week in Stockholm; Saarbrzcken; VDM Verlag Dr. Mueller e.K.

Sun S, Wang Y, Liu J, Cai H, Wu P and Geng Q et al. 2016 Sustainability assessment of regional water resources under the DPSIR framework; J. Hydrol. 532 140-148.

Tal A 2016 Rethinking the sustainability of Israel's irrigation practices in the Drylands; Water Res. 90 387-394.

UN 2015a The United Nations World Water Development Report 2015: Water for a sustainable world; United Nations.

UN 2015b Transforming our world: The 2030 agenda for sustainable development; United Nations.

UN 2018 The United Nations World Water Development Report 2018: Nature-based solutions for water; United Nations.

Vaidyaab O S 2006 Analytic hierarchy process: An overview of applications; Eur. J. Oper. Res. 169(1) 1-29.

Wang G, Xu C and Li D 2014 Generic normal cloud model; Inf. Sci. $\mathbf{2 8 0 ( 2 8 0 ) ~ 1 - 1 5 . ~}$

Corresponding editor: RAJIB MAITY
Wang M, Sun Y, Hou J, Wang X, Bai X and Wu C, et al. 2017 A comparison of food crispness based on the cloud model; $J$. Texture Stud. 49(1).

Wang Y, Yin X, Jing H, Liu R and Su H 2016 A novel cloud model for risk analysis of water inrush in karst tunnels; Env. Earth Sci. 75(22) 1450.

Wu J, Li P, Qian H and Chen J 2015 On the sensitivity of entropy weight to sample statistics in assessing water quality: Statistical analysis based on large stochastic samples; Env. Earth Sci. 74(3) 2185-2195.

Xu S D, Geng X L and Dong X Q 2018 Improved FMEA approach for risk evaluation based on cloud model; Comput. Eng. Appl. 54(2) 228-233.

Yan L, Ma J, Deng W and Wang Y 2018 International comparison of water resources utilization efficiency in the Silk Road economic belt; IOP Conf. Ser., Earth Environ. Sci. 128012041.

Yang L Y, Xu X Y and Jia X X 2009 Water use efficiency evaluating index system; J. Beijing Normal Univ., Nat. Sci. 45(5-6) 642-646.

Yu S and Lu H 2018 An integrated model of water resources optimization allocation based on projection pursuit modelGrey Wolf optimization method in a transboundary river basin; J. Hydrol. 559.

Zhang T, Yan L and Yang Y 2018a Trust evaluation method for clustered wireless sensor networks based on cloud model; Wirel. Netw. 24(3) 777-797.

Zhang X, Meng Y, Xia J, Wu B and She D X 2018b A combined model for river health evaluation based upon the physical, chemical, and biological elements; Ecol. Indic. $\mathbf{8 4}$. 